\title{
Stagnation Point Heat Flux Measurements in a Plasma Wind Tunnel Using a Diamond Heat Transfer Gauge
}

\author{
Rowland T. Penty Geraets* and Matthew McGilvray ${ }^{\dagger}$ \\ University of Oxford, Oxford, U.K. \\ Stefan Loehle ${ }^{\ddagger}$ and Fabian Hufgard ${ }^{\S}$ \\ Universität Stuttgart, Institut für Raumfahrtsysteme, Stuttgart, Germany
}

\begin{abstract}
A Diamond Heat Transfer Gauge has been used to measure the stagnation point heat flux at three flow conditions in an arc heated plasma wind tunnel. The gauge was coated with a thin layer of copper to provide a known surface catalycity and reflectivity. The temperature dependent impulse response of the probe was determined from a finite element model of the probe, and from the result of a laser-based calibration experiment using the Non-Integer System Identification method. The two sets of impulse responses were used to calculate heat flux from a measured temperature rise in the wind tunnel. Differences between the impulse responses from the two methods, particularly at higher initial temperatures, led to differences in measured heat fluxes of up to $55 \%$. A measurement taken using a steady state calorimeter gauge did not conclusively agree with heat flux measurements calculated using impulse responses from either method.
\end{abstract}

\section{Introduction}

Protecting astronauts, samples, and spacecraft during atmospheric entry is of utmost importance to the success of space missions. The aero-thermodynamic environment which a vehicle will experience is both extreme and complex: the bow shock created in front of a vehicle entering earth's atmosphere from a super-orbital trajectory will heat the air to thousands of degrees Kelvin. Complex coupled flow interactions occur, with significant amounts of dissociation and ionisation, large surface convective and radiative heat loads, surface catalytic effects, and interactions with ablation products.

Ground test facilities are needed to understand the re-entry environment, but no single ground test facility can simultaneously replicate all of the conditions. Plasma wind tunnels are capable of producing continuous high enthalpy flows which can be used to test thermal protection materials at conditions representative of super-orbital atmospheric entry [1]. The chemical composition, total pressure, and local mass-specific enthalpy must be known in order to characterise the flow [2].

A measurement of stagnation point surface heat flux to a blunt body probe is needed to estimate the mass-specific enthalpy of the flow [3]. Classical calorimeter style gauges or null-point calorimeters are typically used for this measurement [4-6]. Different types of heat flux gauge and different calibration methods used with the same gauge produce variations in surface heat flux measurements of up to $20 \%$ [7], leading to significant uncertainty in the characterisation of the flow.

Recent studies using high speed photography [8] and high speed spectroscopy of plasma flows at IRS have shown sub-millisecond fluctuations and short high intensity events, which could be due to arc attachment in the generator [9]. Measurements of how these events affect the transient surface heat transfer to a probe have not yet been made. Due to the long run-time of plasma wind tunnels, producing sensors with fast response times has not been a high priority.

To measure a transient surface heat flux, a measurement of temperature is taken and then the Inverse Heat Conduction Problem is solved (IHCP) [10, 11]. The IHCP is a classic ill-posed problem; small errors or noise in the measurement of temperature can lead to instability and large, non-physical measurements of heat flux. The inversion from temperature to heat flux requires either that the thermophysical and geometric properties of the gauge are known, or that the impulse response of the system is known. Provided the gauge can be described as a linear time-invariant system, the impulse

\footnotetext{
*DPhil Candidate, Department of Engineering Science, University of Oxford

$\dagger$ Associate Professor, Department of Engineering Science, University of Oxford

${ }^{\dagger}$ Research Scientist, Group Leader, High Enthalpy Flow Diagnostics, IRS

${ }^{\S}$ PhD Candidate, High Enthalpy Flow Diagnostics, IRS
} 
response fully characterises the response of the gauge [12]. Experimental determination of the impulse response reduces uncertainty arising from inaccurate geometric measurements and assumption of thermophysical properties.

The heat transfer gauge used in this study, the Diamond Heat Transfer Gauge (DHTG), was developed at the University of Oxford for use in short-duration hypersonic facilities [13]. A thin disk of synthetic diamond is used to protect a platinum thin-film resistance temperature detector (RTD) from direct contact with flow. The response time of the gauge is less than $50 \mu \mathrm{s}$, and for test durations of less than $100 \mathrm{~ms}$ the gauge resembles that of as a slug calorimeter. For longer duration tests, heat conduction out of the gauge becomes an important factor and a more complex analysis and calibration is needed. In a previous study, the impulse response of the DHTG was found using a short duration pulsed laser [14], however the duration of the impulse response measured was limited to $100 \mathrm{~ms}$.

In the current study, a DHTG mounted at the stagnation point of a $50 \mathrm{~mm}$ diameter hemispherical probe was used to make heat transfer measurements in the PWK4 wind tunnel at IRS Stuggart. This facility is an arc-heated plasma wind tunnel capable of generating continuous high enthalpy supersonic air plasma flows. The probe was passed quickly across the flow, with a passage time of approximately $1.5 \mathrm{~s}$. The long duration of the experiment in comparison to previous studies with the DHTG required the impulse response of the gauge to be determined on a much longer time-scale. The impulse response was determined using both the Non-Integer System Identification (NISI) method, developed at IRS Stuttgart [5, 15, 16], and a Finite Element (FE) model of the probe. The NISI method involves using a laser to apply a known heat flux, usually a train of square-wave pulses of varying length, to the surface of a gauge and measuring the temperature response. From the input-output pair of heat flux and temperature, the impulse response is identified. In both the NISI calibration experiments and the FE model, the gauge was pre-heated to elevated temperatures to capture the temperature dependence of the impulse response [17]. The impulse responses from both the NISI method and the FE model were used to process experimental temperature measurements into surface heat flux using the Sequential Function Specification Method [18] to solve the IHCP.

\section{The Probe}

The probe comprises a Diamond Heat Transfer Gauge (DHTG) [13] mounted at the stagnation point of a $50 \mathrm{~mm}$ diameter hemisphere made from oxygen-free copper. A cross-sectional schematic can be seen in Fig. 1 The hemispherical probe head was mounted onto a brass probe core, through which signal cables were routed and cooling water was supplied to prevent excessive temperatures during wind tunnel testing.

The DHTG consists of a disk of polycrystalline CVD (Chemical Vapour Deposition) diamond with a platinum thin-film RTD sputtered on the rear surface, mounted in a steel body using high temperature ceramic-based adhesive. The diamond disk has a diameter of $2.5 \mathrm{~mm}$ and a thickness of $325 \mu \mathrm{m}$. The surface of the gauge visible to the flow is coated with $1 \mu \mathrm{m}$ layer of copper to provide a known reflectivity during laser calibration, and a known catalytic efficiency during wind tunnel experiments. Two nominally identical gauges, DHTG26 and DHTG27, were used throughout the study.

As the temperature of the thin-film changes, so does its electrical resistance. A constant current of $10 \mathrm{~mA}$ is applied in an experiment, and the voltage across the film is recorded. The change in temperature can then be calculated using Eq. (1). The coefficient of resistance with temperature, $\alpha_{R}$, is determined for each gauge using the calibration process described by Ref. [19]. Although the calibration is only performed up to $80^{\circ} \mathrm{C}$, the resistivity of platinum is linear up to $50{ }^{\circ} \mathrm{C}$ [20], and so the calibration can be extrapolated up to this limit. The reference temperature $\left(T_{r e f}\right)$ and voltage $\left(V_{r e f}\right)$ are recorded at an isothermal condition immediately prior to each experiment.

$$
T(t)=\frac{V(t)-V_{r e f}}{\alpha_{R} V_{r e f}}+T_{r e f}
$$

The Inverse Heat Conduction Problem is solved to find the surface heat flux using the Sequential Function Specification Method (SFSM) [18]. The method, Eq. (2), sequentially estimates the heat flux at each time-step of the discretised temperature signal by minimising, in a least-squares sense, the difference between the measured temperature, $Y$, and the temperature calculated by solving the direct problem using the prior estimated heat fluxes, $\hat{T}$. The solution is stabilised by assuming that the heat flux for the next $r$ future time-steps is constant. A more detailed description of the procedure is described by Beck [18]. $M$ is defined as the current time-step, $n$ is the length of the discretised measured temperature, $M=1,2,3, \ldots, n$. The sensitivity coefficient $\phi$ is the impulse response, $h$, multiplied by the time-step of the temporal discretisation, i.e. $\phi_{i}=h_{i} d t$. 


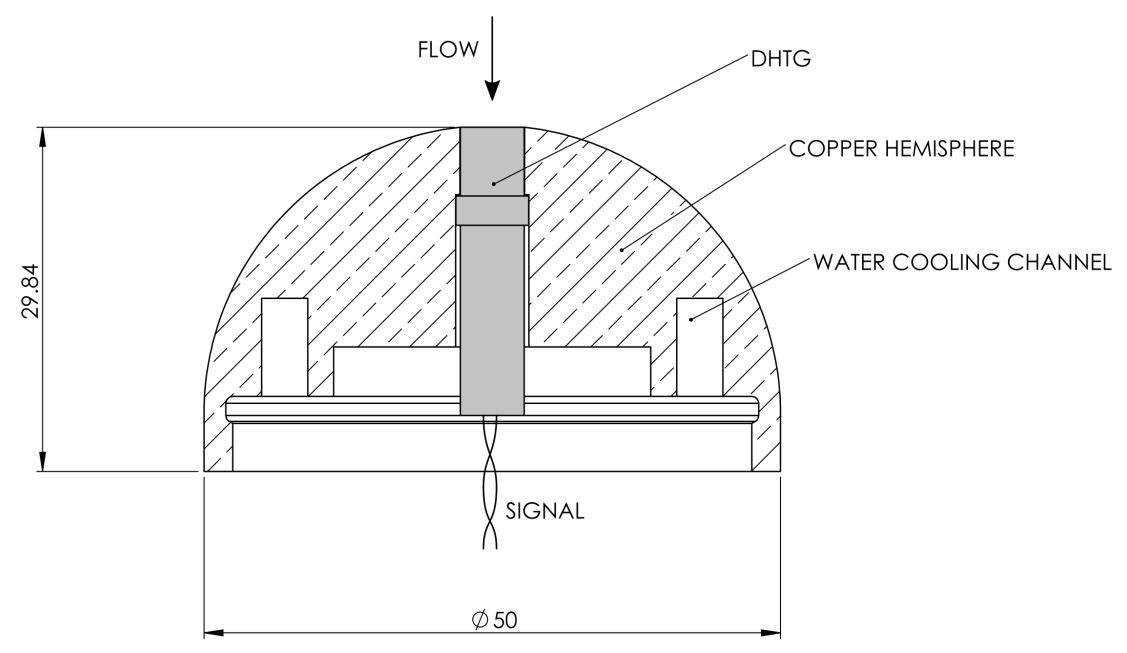

Fig. 1 A cross-sectional schematic of the probe used for experimental testing in PWK4 with a DHTG installed at the stagnation point. Dimensions are in millimetres.

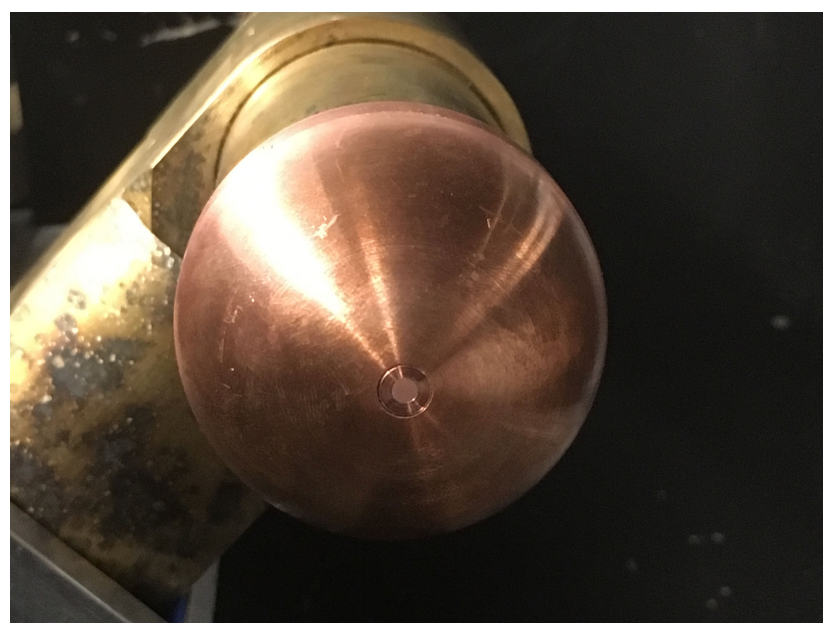

Fig. 2 The probe with DHTG26 installed prior to calibration and testing. The surface of the copper-coated DHTG can be seen at centre of the copper hemisphere. 


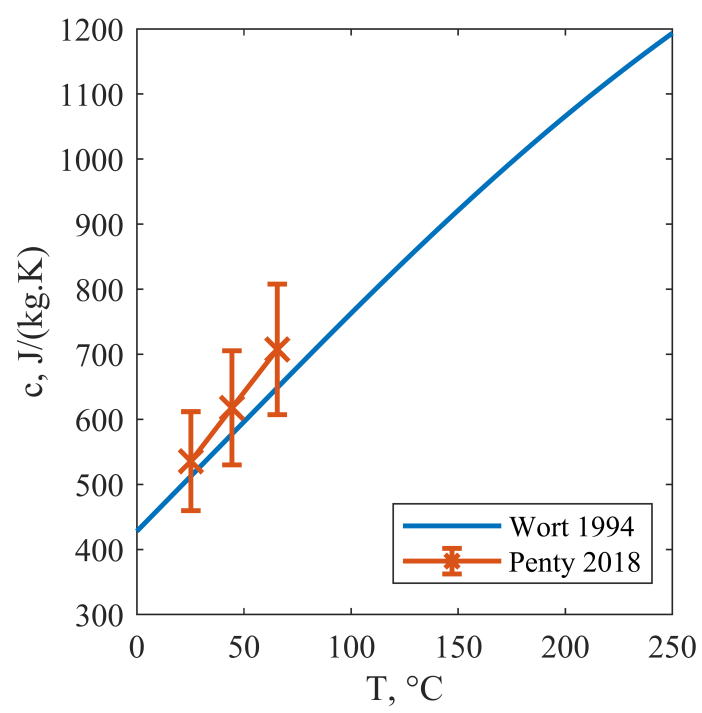

Fig. 3 The specific heat capacity of CVD diamond as a function of temperature [14, 21].

$$
\begin{gathered}
\hat{q}_{M}=\sum_{i=1}^{r} K_{i}\left(Y_{M+i-1}-\hat{T}_{M+i-1 \mid q_{M}=\ldots=0}\right) \\
\hat{T}_{M+i-1 \mid q_{M}=\ldots=0}=\sum_{j=1}^{M-1} \hat{q}_{j} \phi_{M-j+r-1}(T)+T_{0} \\
K_{i}=\frac{\phi_{i}(T)}{\sum_{j=1}^{r} \phi_{j}^{2}(T)}
\end{gathered}
$$

The original algorithm is adapted here to account for an impulse response which is temperature dependent. This non-linearity is driven primarily by the temperature dependence of the specific heat capacity of diamond, as shown in Fig. 3 The impulse response is updated according to the temperature measured by the thin-film at each time-step. By assuming the impulse response to be constant during each time-step, but changing between each time-step, a pseudo-non-linear solution is obtained.

The optimal value of future time-steps, $r$, is found by trial and error: using a low value can amplify noise and lead to instability, whereas using a large value can attenuate high frequency components of the heat flux signal, and lead to under-predictions in measured heat flux.

\section{Impulse Response Determination}

This section details two methods to find the temperature-dependent impulse response of the probe: firstly the Non-Integer System Identification method, and secondly a Finite Element model. The results from the two methods are then compared.

\section{Non-Integer System Identification}

The NISI method was used to find the impulse response of the two gauges, DHTG26 and DHTG27, at four initial temperatures. A diode laser with a maximum power of $540 \mathrm{~W}$ and a wavelength of $980 \mathrm{~nm}$ was used both to pre-heat the gauges and to provide a pulsed surface heat flux. The face of the DHTG was positioned $277 \mathrm{~mm}$ away from the focusing optics resulting in a laser spot size of $21.4 \mathrm{~mm}$. Fig. 4 shows the laser-head and copper dome probe in an optics enclosure. Cooling water at $20^{\circ} \mathrm{C}$ was supplied to the internal channels (see Fig. 1) throughout the calibration experiment to replicate the conditions of wind tunnel testing. 


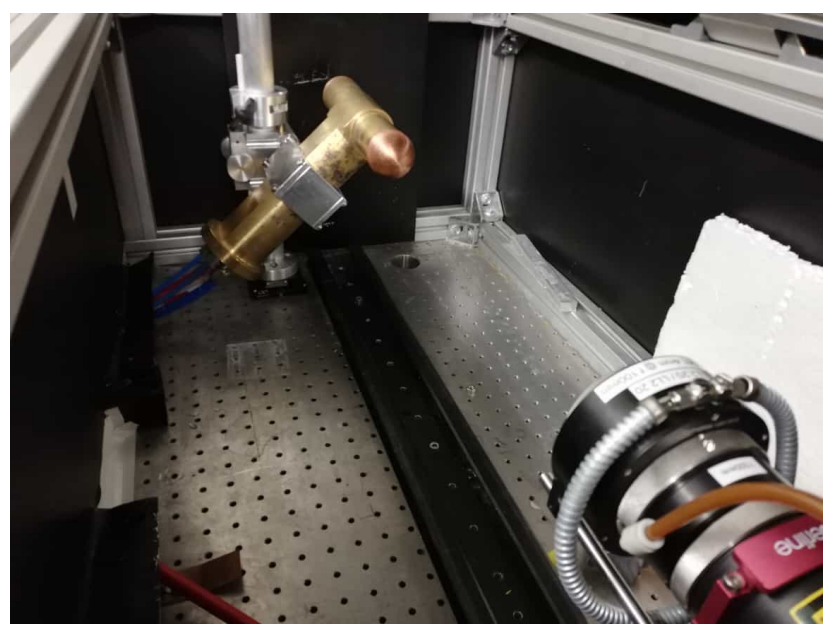

Fig. 4 The NISI calibration set-up at IRS. The laser head is in the foreground and the probe is in the background.

Table 1 Laser optical output power, incident radiative heat flux, and initial temperatures, for the NISI experiments.

\begin{tabular}{lllll}
\hline NISI Condition & $\mathrm{A}$ & $\mathrm{B}$ & $\mathrm{C}$ & $\mathrm{D}$ \\
\hline$P_{0}, \mathrm{~W}$ & 0 & 50.6 & 131.8 & 210.3 \\
$Q_{0}, \mathrm{~kW} / \mathrm{m}^{2}$ & 0 & 140.4 & 366.2 & 584.2 \\
$\Delta P_{\text {pulse }}, \mathrm{W}$ & 83.0 & 93.5 & 133.2 & 140.2 \\
$\Delta Q_{\text {pulse }}, \mathrm{kW} / \mathrm{m}^{2}$ & 231.1 & 259.6 & 285.6 & 389.6 \\
$T_{0},{ }^{\circ} \mathrm{C}(\mathrm{DHTG} 26)$, & 19.4 & 54.3 & 103.1 & 146.7 \\
$T_{0},{ }^{\circ} \mathrm{C}($ DHTG27), & 20.0 & 50.3 & 94.8 & 133.9 \\
\hline
\end{tabular}

To perform an experiment, firstly the laser was turned on at the stated power $P_{0}$ in Table 1 , and the temperature measured by the RTD was allowed to reach a steady state, measured as $T_{0}$. The laser power was then repeatedly pulsed to a high power state of $P_{0}+\Delta P_{\text {pulse }}$, returning to $P_{0}$ between pulses. The pulse train contained a range of pulse durations between $2 \mathrm{~ms}$ and $150 \mathrm{~ms}$. The voltage across the RTD during the experiment was recorded at $200 \mathrm{kHz}$ using an oscilloscope. From the measured voltage, the temperature was calculated using Eq. (1). Figure 5a shows the absorbed surface heat flux and the measured temperature response for DHTG27 at Condition B (see Table 11). The emissivity, and therefore absorptivity, of the copper surface was taken to be that of oxidised copper, i.e. $\epsilon=0.48$ [7, 22]. It has been shown that an oxide layer forms on copper within minutes [6] and the DHTGs and probe body were left exposed to air for over three weeks prior to testing.

The NISI method was used to identify the impulse response shown in Fig. 5b from the experimental data in Fig. 5a The inputs of temperature and heat flux to the NISI process were referenced from a zero point at the equilibrium state just prior to the beginning of the laser pulsing. The data had to be down-sampled from the recording frequency to $200 \mathrm{~Hz}$ for the NISI identification to produce a stable solution. The resulting responses were then filtered with a moving average filter of length $20 \mathrm{~ms}$ to remove oscillations. Between calibrations and wind tunnel testing the gauges were not removed from the probe head so that the thermal contact between the two pieces captured in the calibration experiment was correct.

Figures $5 \mathrm{c}$ and $5 \mathrm{~d}$ are indicators of how well the real system has been identified. In Fig. $5 \mathrm{c}$, the direct heat conduction problem is solved using the absorbed surface heat flux to calculate the temperature response of the identified system. The long-term losses after the pulsing stops are not perfectly matched, but overall the agreement is good. In Fig. 5d, the inverse problem is solved to find the surface heat flux using the experimental temperature rise and the identified impulse response. The cumulative heat load is plotted to illustrate the build up of error in the identified model over time. Despite high levels of noise, good agreement is shown, particularly for the longer duration pulses. 


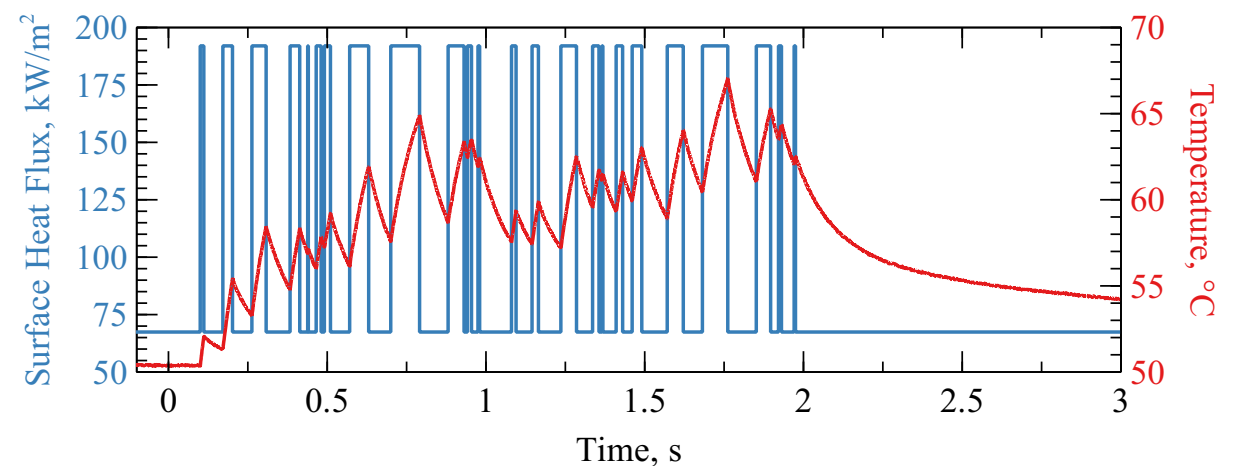

(a) Experimental data.

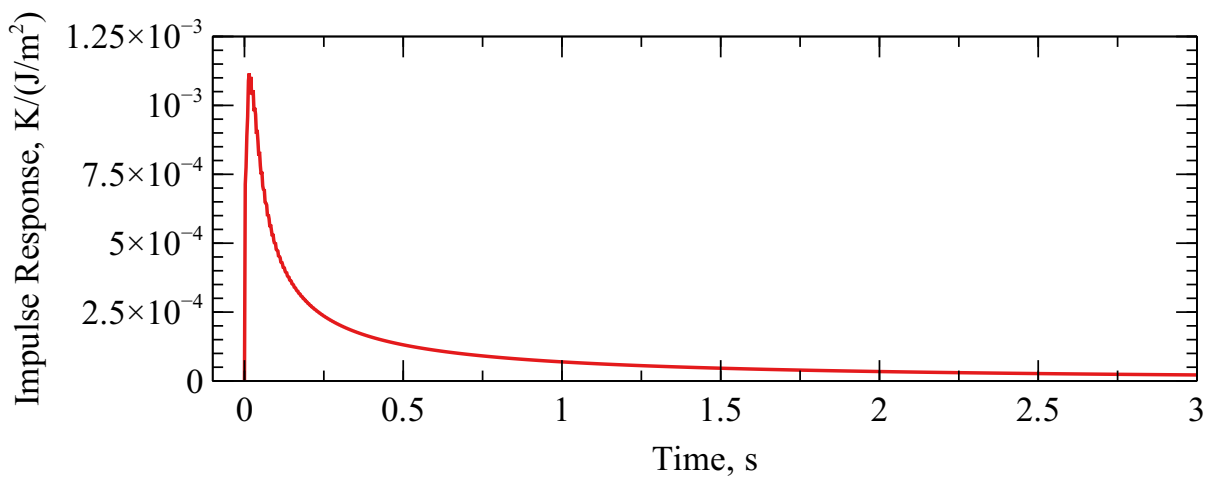

(b) Identified impulse response from NISI.

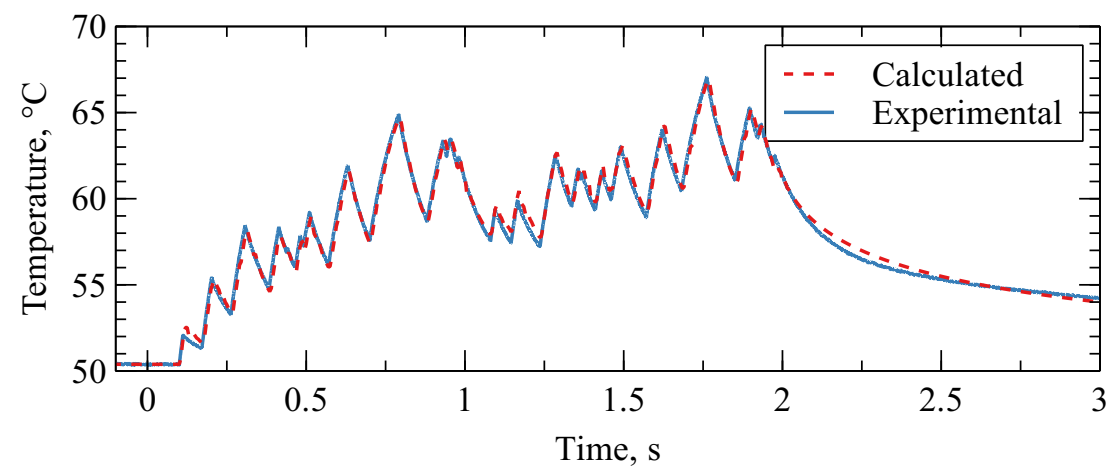

(c) Experimental and calculated temperatures.

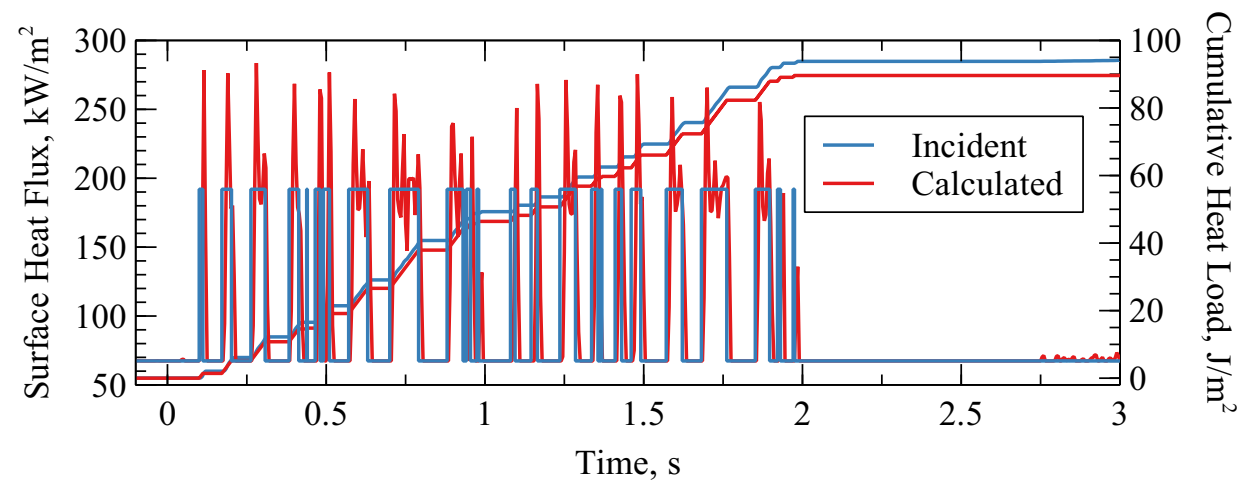

(d) Experimental and calculated surface heat flux and cumulative heat load.

Fig. 5 Experimental data and result of the Non-Integer System Identification experiment for DHTG27 at Condition B in Table 1 . 


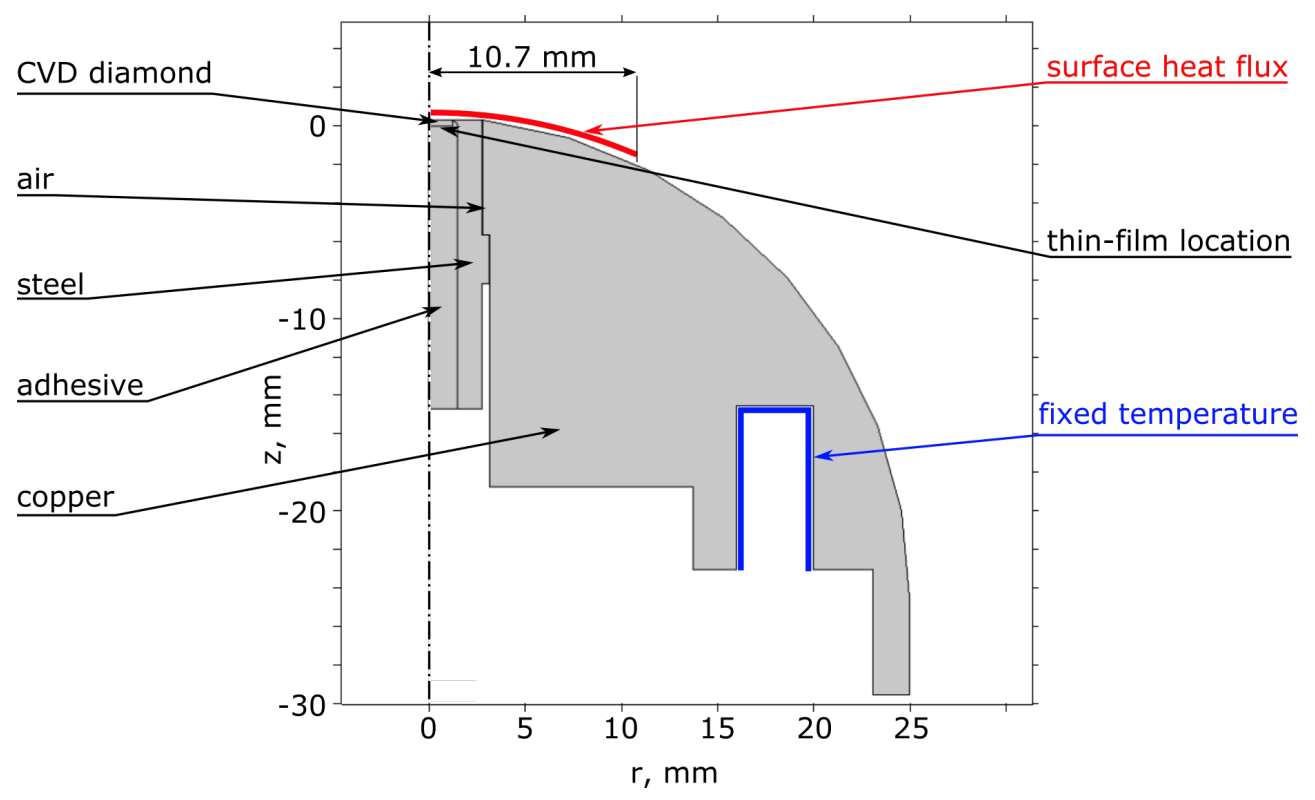

Fig. 6 The Comsol finite element model domain with materials and boundary conditions labelled.

\section{Finite Element model}

A Finite Element (FE) model was used to determine the impulse response of the probe as a comparison to the results from the NISI experiments. The model domain and boundary conditions are shown in Fig. 6. The internal water-cooling was modelled as a fixed temperature boundary condition at $20^{\circ} \mathrm{C}$ on the faces of the internal channel. Surface heating was applied as a heat flux boundary condition on the front surface over the same diameter as the laser spot size in the NISI experiments. In a DHTG, the RTD is on the rear surface of the diamond layer; to provide a comparative temperature from the FE model the surface integrated temperature across this boundary is used, and is called $T_{F E}$. The thermophysical properties of copper were taken to be $\rho=8960 \mathrm{~kg} / \mathrm{m}^{3}, c_{p}=385 \mathrm{~J} / \mathrm{kgK}, k=400 \mathrm{~W} / \mathrm{mK}$; those of steel were taken to be $\rho=7850 \mathrm{~kg} / \mathrm{m}^{3}, c_{p}=475 \mathrm{~J} / \mathrm{kgK}, k=44.5 \mathrm{~W} / \mathrm{mK}$; temperature dependent properties of air were taken from Ref. [23]; temperature dependent CVD diamond properties were taken from Ref. [21]. Only the density and specific heat capacity of the adhesive were provided by the manufacturer, these are $\rho=1875 \mathrm{~kg} / \mathrm{m}^{3}$ and $c_{p}=880 \mathrm{~J} / \mathrm{kgK}$, the thermal conductivity was estimated using the procedure described below. The mesh contained 15,000 triangular elements. Mesh independence was demonstrated by increasing the number of elements by an order of magnitude and observing a maximum difference in $T_{F E}$ of $0.3 \%$ for the impulse response at NISI Condition A shown in Fig. 5a.

An iterative process was used to match the FE model to the physical probe. The pulse of heat flux shown in Fig. $7 \mathrm{a}$ was applied to the surface of DHTG27 immediately after the NISI calibration experiments had taken place, i.e. using the same laser and physical arrangement. The temperature response was measured and is shown in Fig. $7 \mathrm{~b}$. The same heat flux pulse was applied as heat flux boundary condition in the FE model assuming an absorptivity of 0.48 . The simulation was run many times and the thermal conductivity of the adhesive material was iteratively changed until the peak $T_{F E}$ was matched to the experiment. The resulting value of thermal conductivity, $k=0.65 \mathrm{~W} / \mathrm{mK}$, was used for all subsequent simulations. Since the duration of the wind tunnel tests was known to approximately $1.5 \mathrm{~s}$, a perfect match between the model and the experiment is not required beyond this time.

The following method was used to find the impulse response for the probe at each of the four conditions in Table 1 ;

1) Run a steady-state simulation with a surface heat flux (which has been found through trial and error) such that $T_{F E}=T_{0}$, where $T_{0}$ is that for DHTG27 in Table 1 .

2) With the solution to the steady state simulation as the initial condition, run a transient simulation with a step in surface heat flux, $q_{s}=1 \mathrm{~W} / \mathrm{m}^{2}$, starting at $t=0$.

3) The impulse response is defined as the derivative of the step response, therefore, the unit impulse response can be calculated using Eq. (5).

$$
h_{T_{0}}(t)=\frac{1}{q_{s}} \frac{d T_{F E}(t)}{d t}
$$




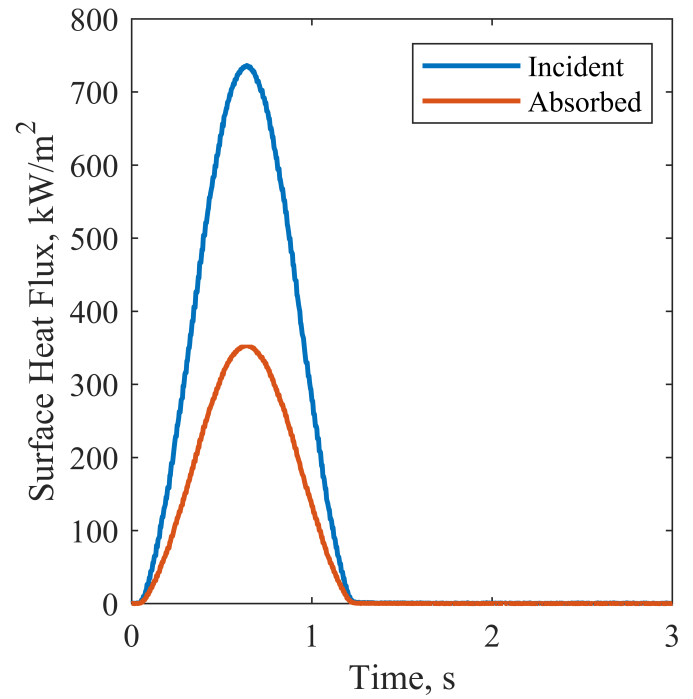

(a)

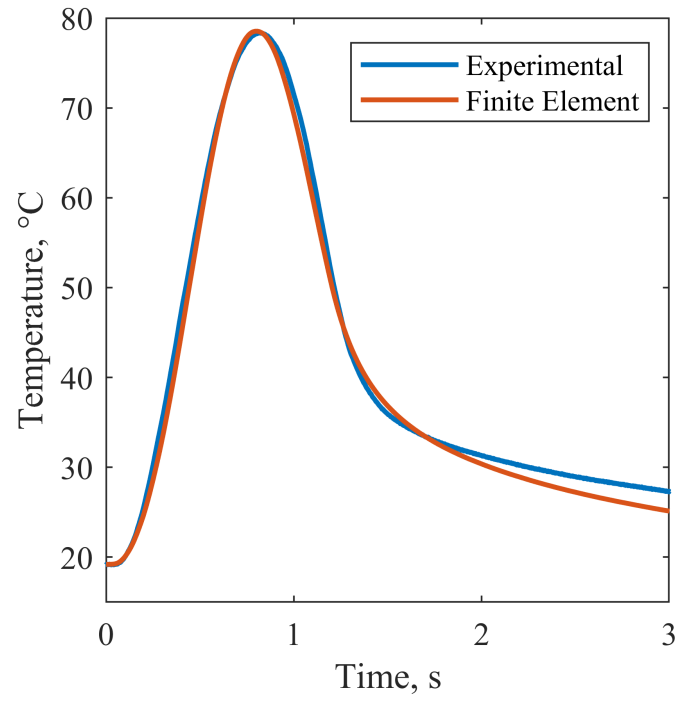

(b)

Fig. 7 The applied heat flux profile and temperature response from experimental measurement and from the FE model.

This calculation assumes $q_{s}$ is sufficiently small such that changes in material properties are negligible. The steady state simulation is performed to match the temperature profile through the whole probe to approximately the same state as would be present in the NISI calibration. The maximum temperature expected in the wind tunnel experiments was $240^{\circ} \mathrm{C}$ but the NISI calibration could not be performed at this temperature due to limits on the laser power. The maximum initial temperature in the FE study was $T_{F E}=250^{\circ} \mathrm{C}$.

\section{Impulse Response Results}

The results from the FE study are shown in Fig. 8 on two different time-scales. The dashed lines in Fig. 8b indicate the impulse response of a fully insulted lumped thermal capacitance of CVD diamond, calculated using Eq. (6) with the same volume and properties as were used in the simulation. On short time-scales the response is dominated by the properties of the diamond, with the peak of the response almost reaching the theoretical maximum. Conductive losses dominate beyond $0.2 \mathrm{~s}$ and the properties of the diamond have less influence on the response.

$$
h=\frac{1}{\rho\left(T_{F E}\right) c_{p}\left(T_{F E}\right) l}
$$

The results from the NISI method and the FE model are compared at each initial temperature in Fig. 9 The impulse responses are plotted as solid lines, and the step responses, which are the time-integrated impulse responses, are plotted as dashed lines. The step responses are shown to illustrate how a difference in area under the impulse response curve grows over time. The impulse responses from the FE model have been filtered to the same level as the NISI impulse responses to allow comparison. The filtering reduces the magnitude of the initial peaks compared to those in Fig. 8

Overall the agreement between DHTG26 and DHTG27 is good, but across all conditions there is a consistent difference in peak amplitude and rate of decay after the peak. Agreement is best between the NISI and FE impulse responses at Condition B. At the lowest temperature condition, A, the NISI-derived responses are higher than those from FE, and at the higher temperature conditions, $\mathrm{C}$ and $\mathrm{D}$, the inverse is true. The difference in step responses grows most quickly in the fist $0.5 \mathrm{~s}$ where there is a difference in peak width and rate of decay. This region of response most dominated by diamond and adhesive material properties, but could also be affected by the large reduction in sampling rate required in the NISI process.

There are two possible reasons for the temperature dependent discrepancy between the two methods. The first, is that the NISI calibration is accurate, and that a temperature dependent effect, such as incorrect material properties, is not 


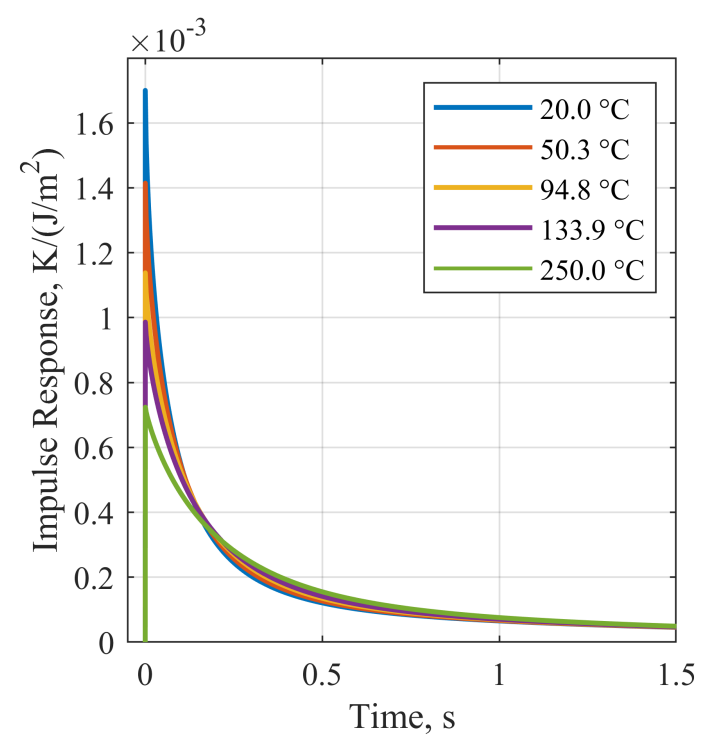

(a)

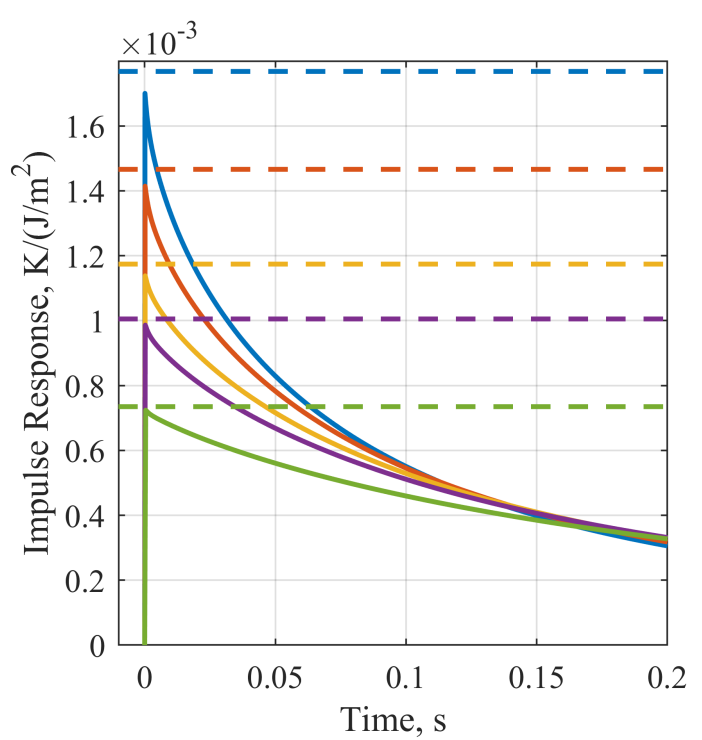

(b)

Fig. 8 Impulse responses from the Finite Element model on two different time-scales. The dashed lines in (b) indicate the calorimetric limit of the diamond layer.

correctly modelled in the FE model. The properties of the CVD diamond used are from the literature [21], validated by a recent study which showed agreement up to $75^{\circ} \mathrm{C}$ (see Fig. 3). The second, is that the FE model is accurate, and that there was either an experimental error in the NISI calibration experiments, an unaccounted for temperature dependent factor in the calculation of absorbed heat flux, or that there is an issue with the identification process at higher pre-heat and pulsed laser powers.

One possible explanation for the difference between the impulse responses is that the assumed emissivity, that of oxidised copper $(\epsilon=0.48)$, is incorrect. If the actual emissivity were closer to that of polished copper $(\epsilon=0.15)$, and constant across the temperature range, all NISI impulse responses would increase in magnitude, but the identified impulse response at Condition A would increase beyond the calorimetric limit of Fig. 8b, which should not be possible. Laser ablation of the oxide layer, which could theoretically polish the surface at higher pulsed laser powers, has been shown to occur only at pulsed irradiation intensities above $125 \mathrm{GW} / \mathrm{m}^{2}$ [24].

\section{Experimental Method}

The PWK4 facility consists of a thermal arc-jet generator, the nozzle of which is attached to a large vacuum chamber measuring two metres in diameter and six metres in length. More information on the facility can be found in Refs. [1] [2]. The three conditions shown in Table 2 were used in the current study. Conditions $1 \mathrm{a}$ and $1 \mathrm{~b}$ use the same generator condition and differ only in the axial distance of the probe from the nozzle exit. DHTG26 was only used at Condition 1a whereas DHTG27 was used at all conditions.

Each experiment started with the probe out of the flow, as shown in Fig. 10. The generator was started, and once the desired condition had been reached, the probe was traversed across the centre until it was out of the flow again at the other side. The total duration which the probe was in the flow was approximately $1.5 \mathrm{~s}$. A fast sweep was used because the DHTG is a transient heat transfer gauge with a short response time; it was not necessary or useful for the gauge to be in the flow for a longer duration. For each condition, the probe was passed across the flow between two and four times. Sufficient time was allowed for probe to cool back down to the temperature of the cooling water $\left(20^{\circ} \mathrm{C}\right)$ between runs.

The voltage across the RTD in the DHTG was recorded with an oscilloscope at a sampling frequency of $250 \mathrm{kHz}$ as the probe passed across the flow. The temperature was then calculated using Eq. (1). The temperature data was down-sampled to $500 \mathrm{~Hz}$ and Eq. (2) was used to calculate the surface heat flux using for both the NISI and the FE impulse responses using a value of $r=2$. At each time-step of recorded experimental data, the current impulse response was updated using an interpolation between the impulse responses shown in Section III..3. A constant extrapolation 


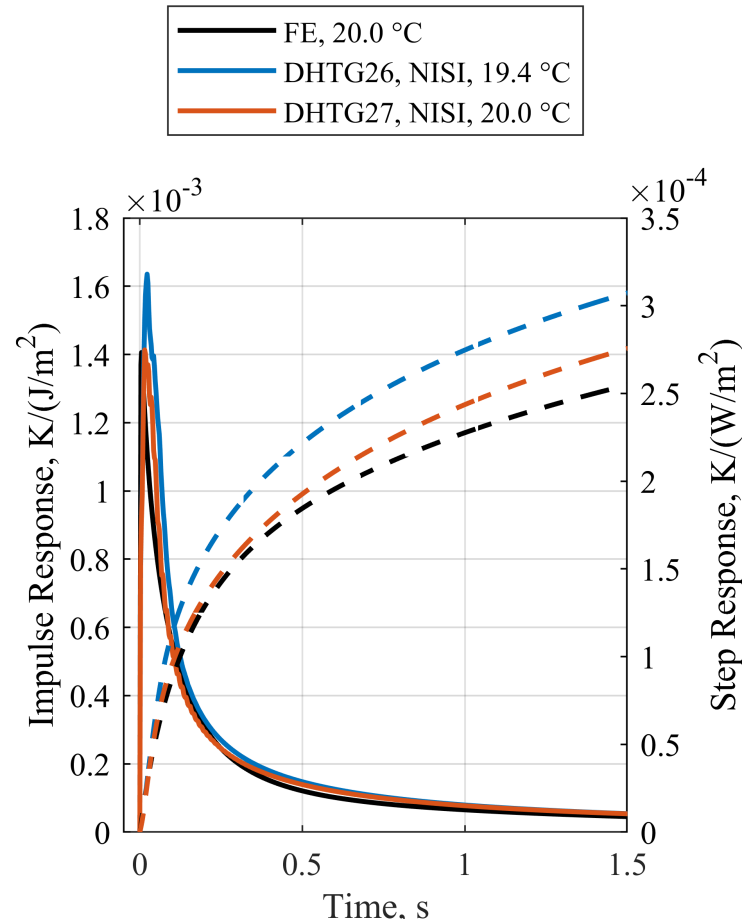

(a) NISI Condition A

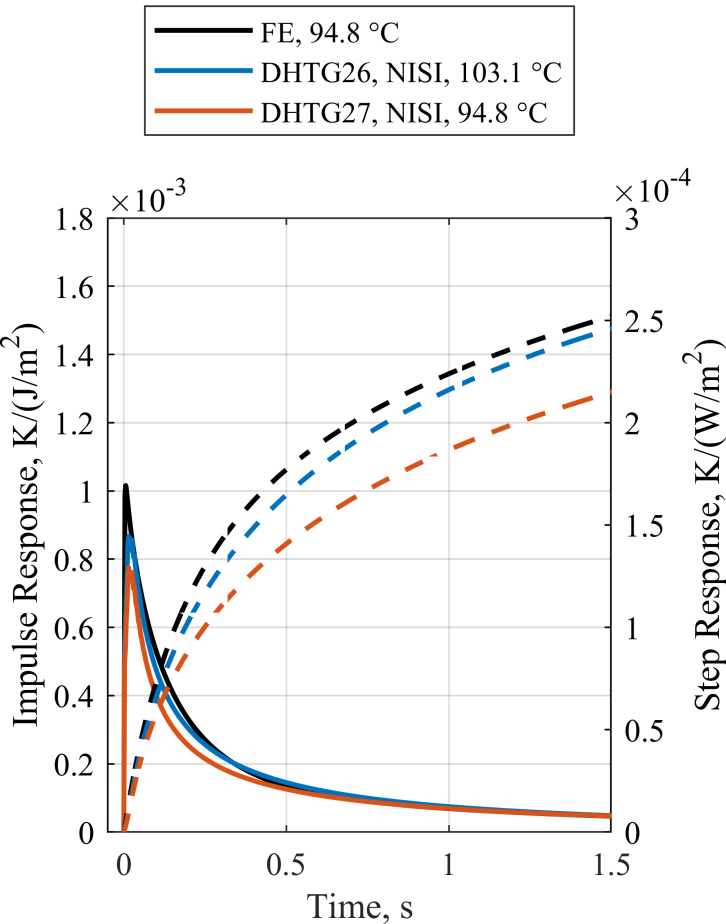

(c) NISI Condition C

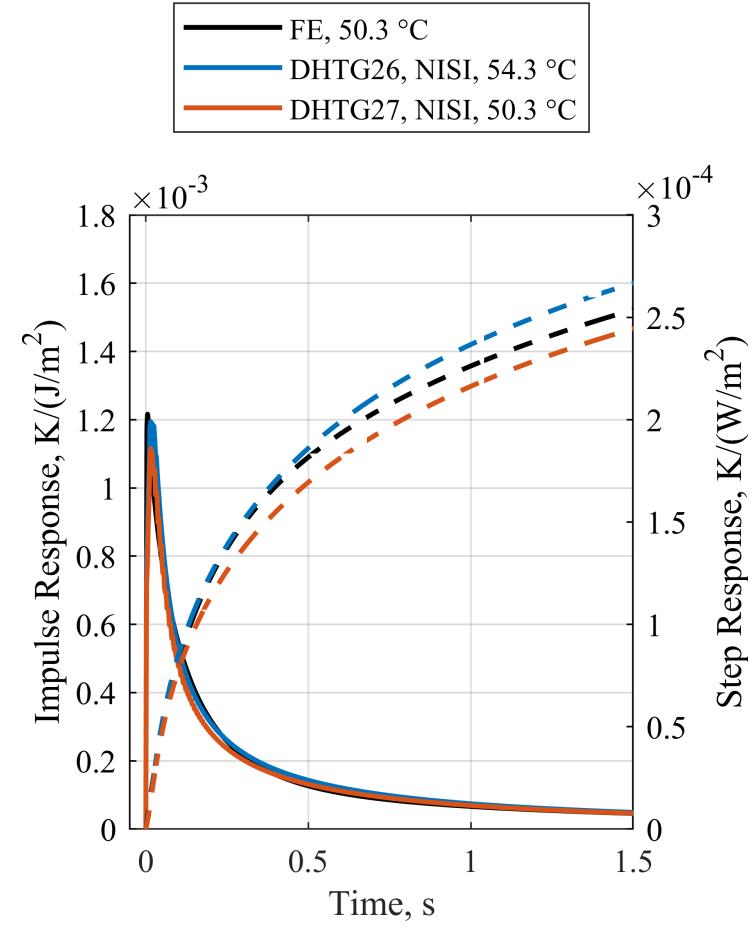

(b) NISI Condition B

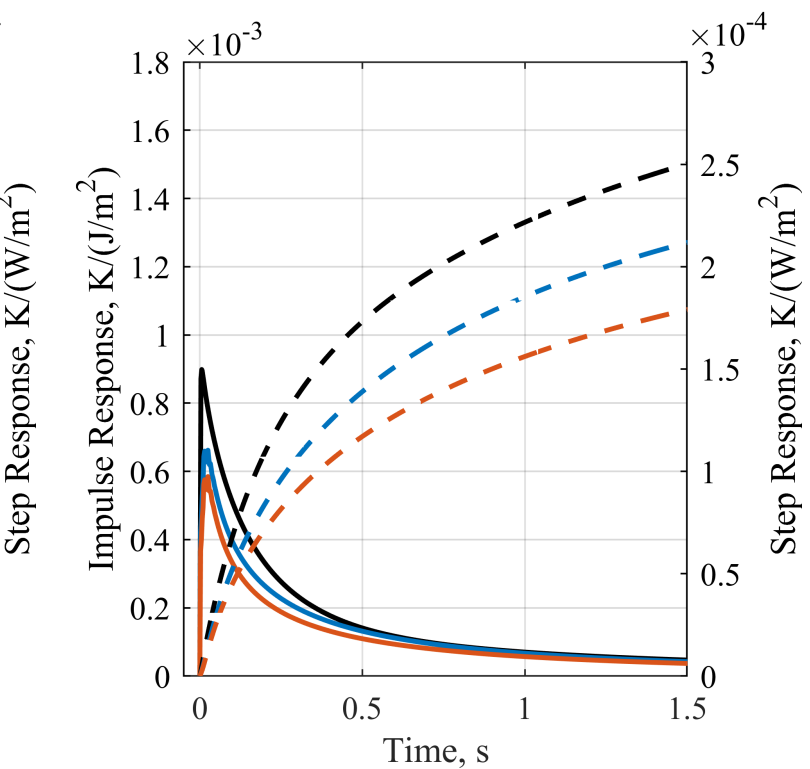

(d) NISI Condition D

Fig. 9 Impulse responses (solid lines) and step responses (dashed lines), at four initial temperatures for both DHTG26 and DHTG27 from the NISI method and from the FE model. 
Table 2 A table of the three conditions used for the experiments in PWK4. Conditions 1a and $1 \mathrm{~b}$ are the same flow condition but with the probe at a different axial distance from the nozzle.

\begin{tabular}{llll}
\hline Condition & $1 \mathrm{a}$ & $1 \mathrm{~b}$ & 2 \\
\hline Ambient pressure, $p_{a m b}(\mathrm{mPa})$ & 153 & 152 & 3300 \\
Generator Current, $I(\mathrm{~A})$ & 602.0 & 602.0 & 635.4 \\
Generator Voltage, $U(\mathrm{~V})$ & 93.1 & 93.2 & 93.4 \\
Electric input power, $P_{e l}(\mathrm{~kW})$ & 56.0 & 56.1 & 59.3 \\
Nitrogen mass flow, $\dot{m}_{N 2}(\mathrm{~g} / \mathrm{s})$ & 5.0 & 5.0 & 5.0 \\
Oxygen mass flow, $\dot{m}_{O 2}(\mathrm{~g} / \mathrm{s})$ & 1.52 & 1.52 & 1.52 \\
Axial position, $x(\mathrm{~mm})$ & 90 & 208 & 90 \\
Total pressure, $p_{\text {tot }}(\mathrm{Pa})$ & 1243 & & \\
\hline
\end{tabular}

was used where the experimental temperature went above the maximum temperature which the NISI experiments were performed at. Extrapolation was not required for the FE impulse responses.

\section{Uncertainty Analysis}

Uncertainty $(u)$ in a measured quantity which is dependent on multiple variables can estimated using the RootSum-Square method [25], Eq. 77). Combining error in the variables associated with measuring temperature in Eq. 1 ] gives $u_{T}=1.7 \%$. The uncertainty in the impulse response from the NISI method is a function of the laser power $(10 \%)$, the laser spot area $(5 \%)$, the measured temperature $(1.7 \%)$ and the emissivity, which is estimated to be at minimum $10 \%$. These combine to give an uncertainty of $u_{\text {NISI }}=15.1 \%$. An additional uncertainty which cannot be estimated stems from the imperfect fit of the system identified by the NISI procedure to the real system. The impulse responses calculated using the FE model are most influenced by the material properties of the CVD diamond and the glue substrate over short time-scales and by the properties and geometry of the entire domain on longer time-scales. A systematic analysis of how error these errors propagate through the simulation to impulse response has not been performed. Uncertainty in the experimental heat flux measurements is due to uncertainty in the temperature measured and the impulse responses. Combining these values from above gives an $u_{q, N I S I}=15.1 \%$. This is believed to be a lower bound, as there are uncertainties which could not be estimated.

$$
\Delta u_{f, R S S}=\sqrt{\sum_{i=1}^{N}\left(\frac{\partial f}{\partial x_{i}} \Delta x_{i}\right)^{2}}
$$

\section{Experimental Results}

Experimental temperature rise and calculated surface heat flux are shown for Condition 1a with DHTG26 in Fig. 11 , for Condition 1a with DHTG27 in Fig.12, for Condition 1b in Fig. 13, and for Condition 2 in Fig. 14, The measurements of temperature have been shifted in time to align the peaks. The heat flux data was filtered using a moving average filter with a length of $40 \mathrm{~ms}$. For Condition 1a, a heat flux measurement was made with a steady-state hemispherical copper calorimeter probe [3], the measured value was $2.083 \mathrm{MW} / \mathrm{m}^{2}$ with an uncertainty of $20 \%$.

For even run numbers, the probe traversed from left to right across the flow (when looking into the nozzle), and for odd numbers from right to left. An under-shoot in measured heat flux can be seen for all runs when the probe exits the flow and cools, and is larger for the heat fluxes calculated with the NISI impulse responses. This indicates that the identified impulse responses have not correctly captured the physical system because the negative heat flux is not physical. Condition 1a and $1 \mathrm{~b}$ use the same generator condition, but the probe is further away from the nozzle exit, and therefore the heat flux measured is lower. The flow also expands as it progresses away from the nozzle resulting in the broader heat flux peak shown.

The heat fluxes calculated using the NISI impulse responses are between $45 \%$ and $55 \%$ higher than those calculated using the FE impulse responses. The difference is due to the difference in magnitude of the respective impulse responses, 


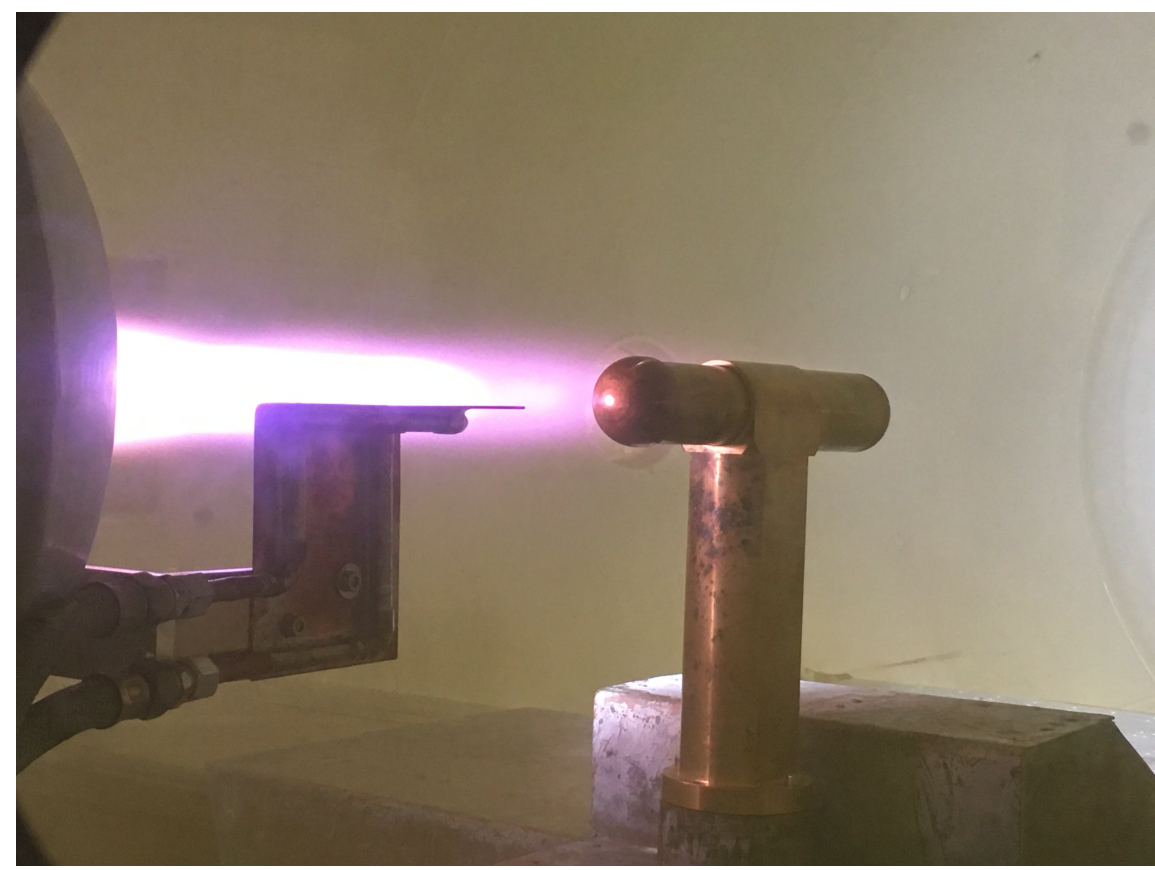

Fig. 10 The probe in PWK4 just prior to traversing across the plasma flow, which can be seen glowing purple.

particularity at higher temperatures, as shown in Fig. 9 There is a difference of up to $15 \%$ between the measurements with DHTG26 and DHTG27 at Condition 1a. Unfortunately, due to recent changes to the wind tunnel of unknown origin, the heat transfer data cannot be compared to existing measurements in the literature, even at the same nominal condition. The only comparative measurement available is that taken with the steady state calorimeter for Condition 1a, where good agreement is shown with the FE-derived heat fluxes for DHTG27 and with the NISI-derived heat fluxes for DHTG26. An increase of up to $30 \%$ in measured heat flux has been observed when an initially polished copper calorimeter has been left in a pure oxygen plasma wind tunnel for 30 minutes. The change is assumed to be caused by an increase in surface catalytic efficiency due to surface oxidation. The total amount of time which each DHTG spent in the plasma flow was less than $30 \mathrm{~s}$. No correction has been applied to account for a difference in catalycity between the calorimeter probe and the DHTG because the surface oxidation state of the DHTG is unknown.

Fluctuations in surface heat flux caused by unsteadiness in the flow were investigated by processing the temperature data, this time low-pass filtered at $5 \mathrm{kHz}$, using the FE impulse responses. The NISI impulse responses are limited to $200 \mathrm{~Hz}$ (see Section III..1). The power spectra of the resulting signals were analysed but no obvious peaks indicative of events occurring at constant repetition rates in the generator were seen. With the reduction in filtering, much higher noise levels were seen which may have hidden data. 
Distance from Centre, $\mathrm{mm}$

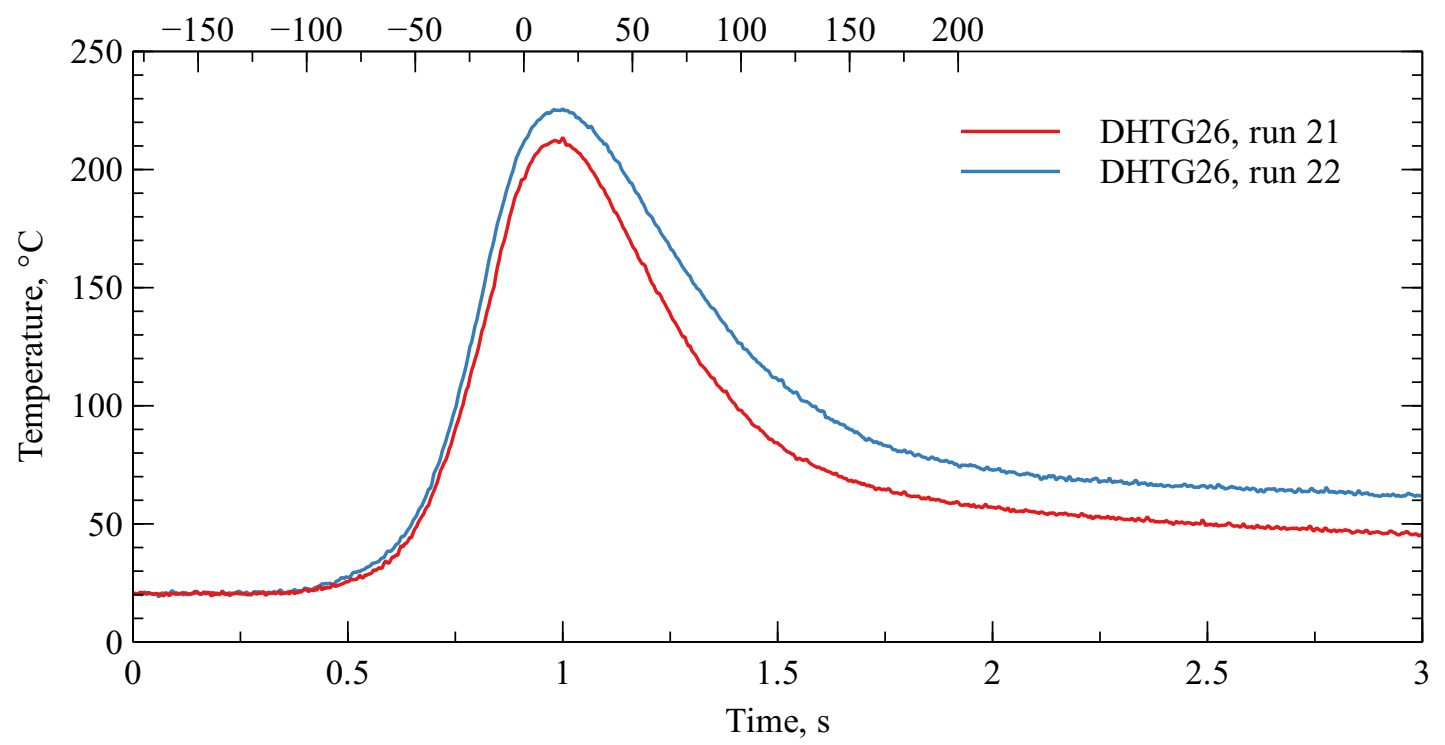

(a) Temperature

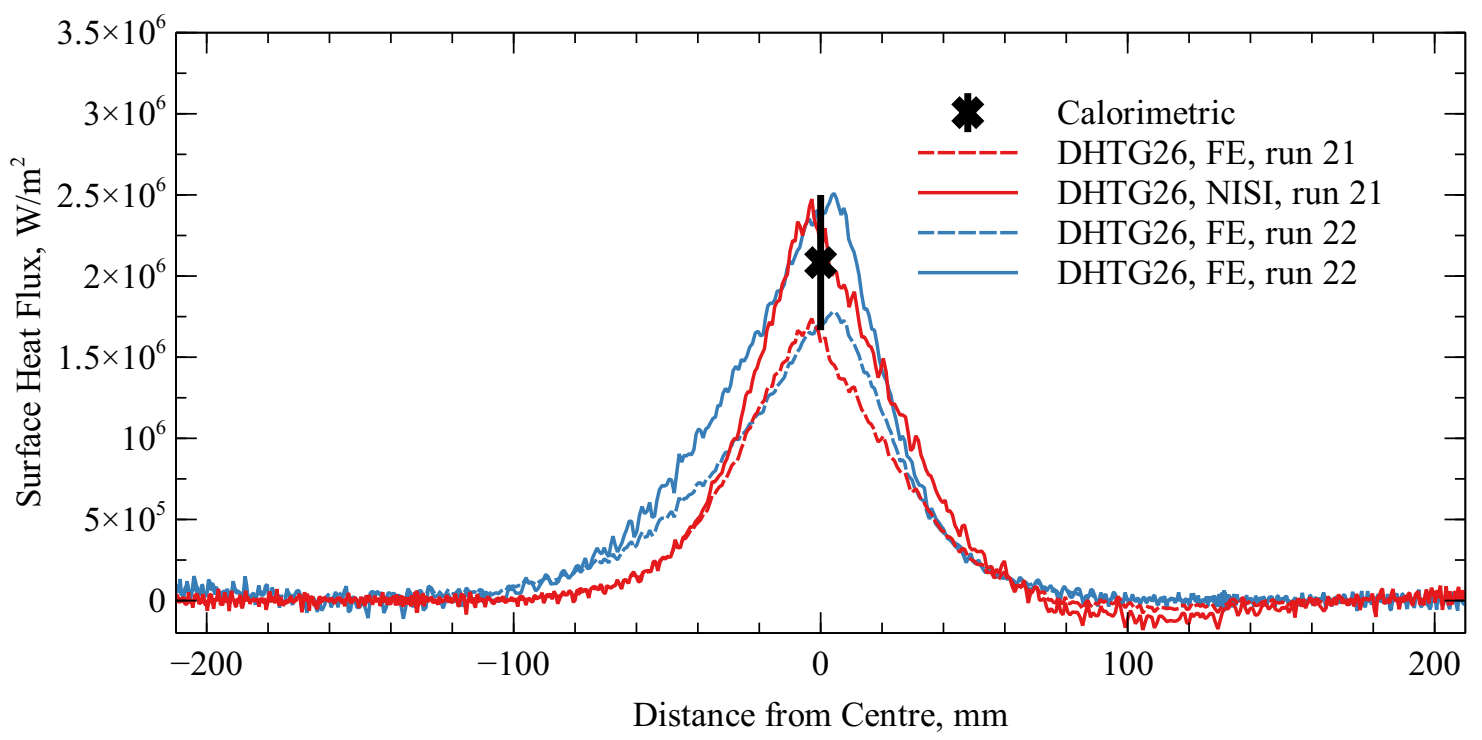

(b) Surface Heat Flux

Fig. 11 Measurements of temperature and heat flux for DHTG 26 at Condition 1a in PWK4. 
Distance from Centre, $\mathrm{mm}$

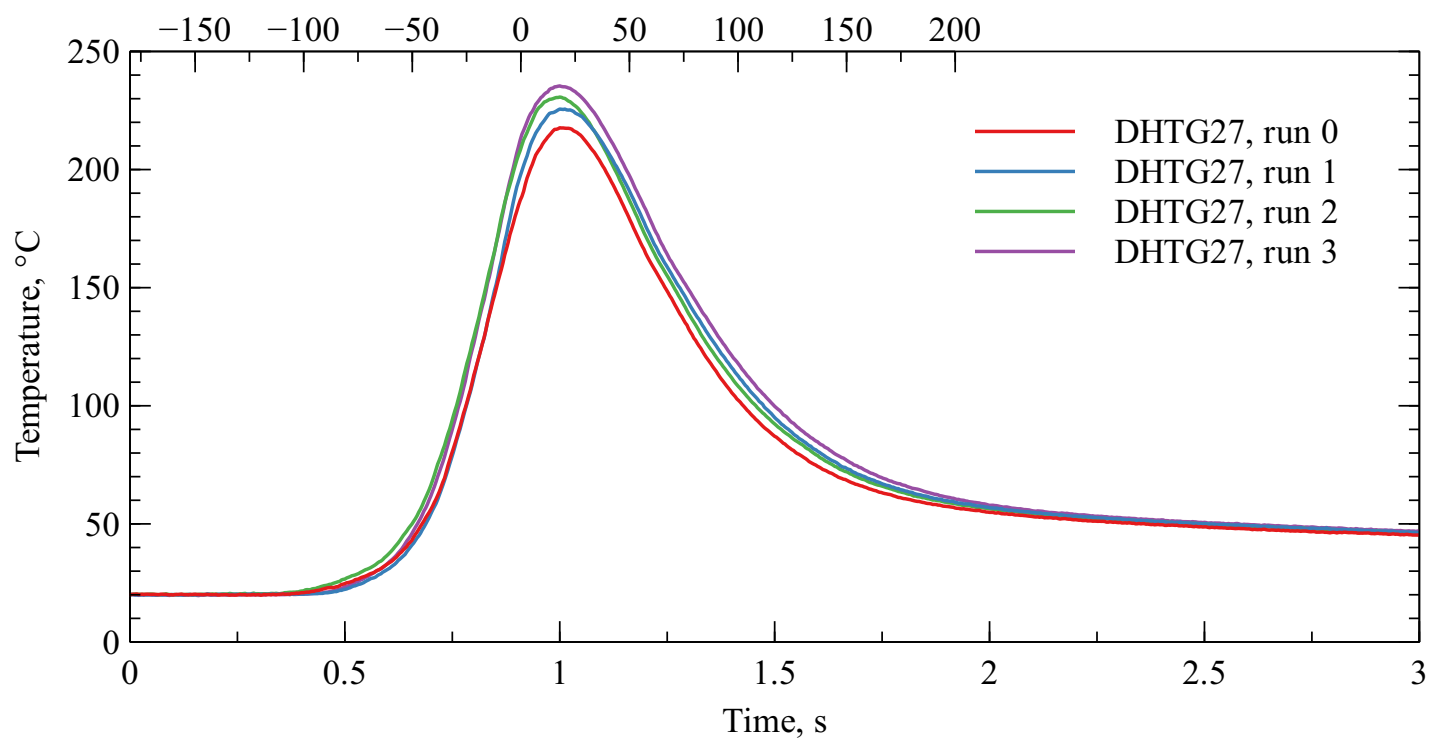

(a) Temperature

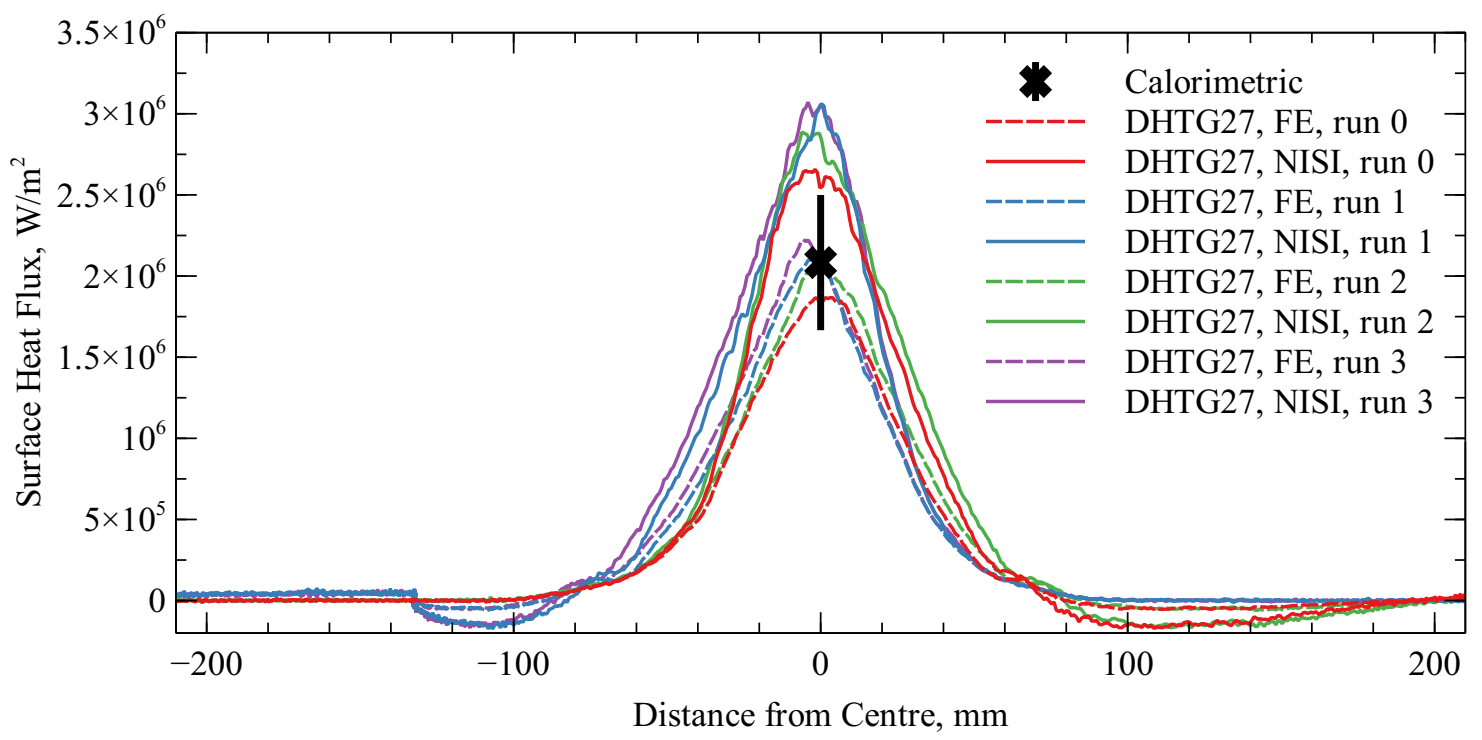

(b) Surface Heat Flux

Fig. 12 Measurements of temperature and heat flux for DHTG 27 at Condition 1a in PWK4. 
Distance from Centre, $\mathrm{mm}$

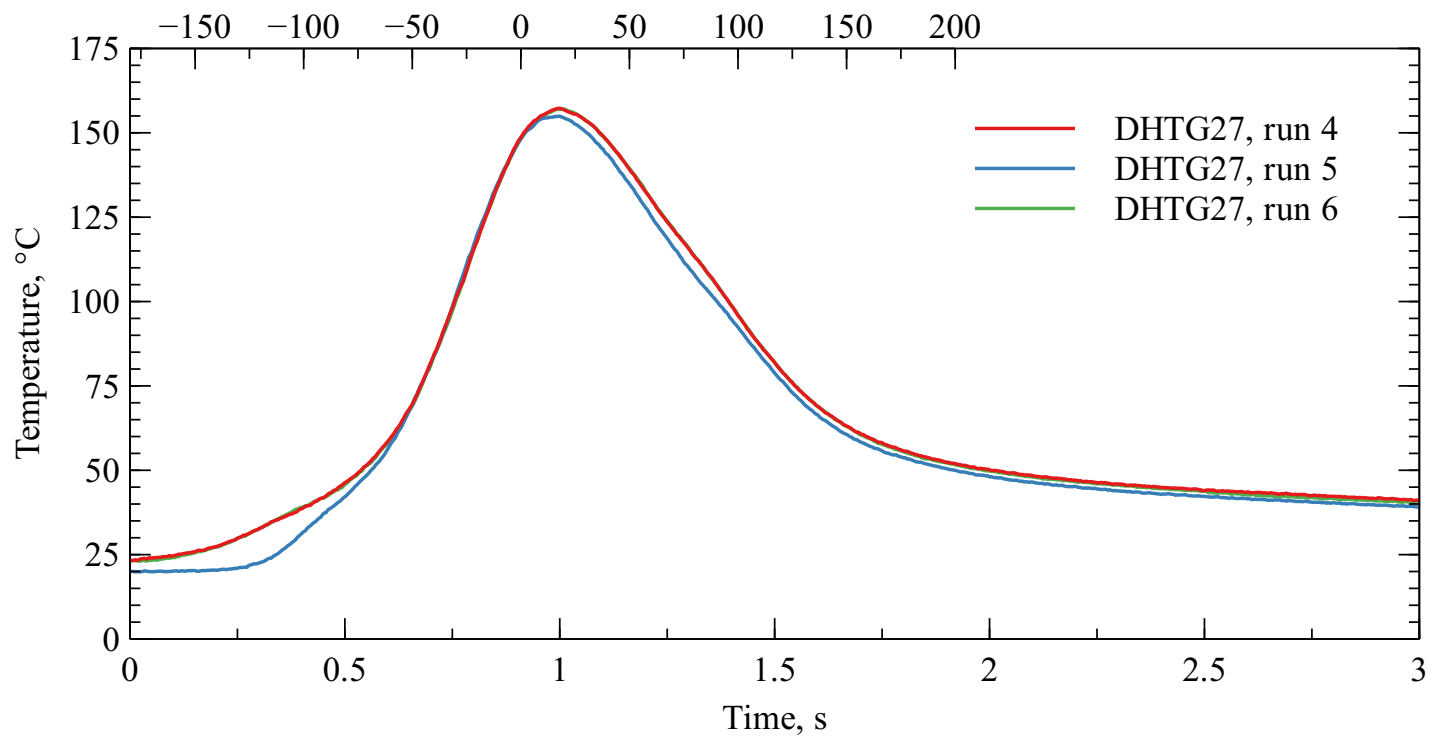

(a) Temperature

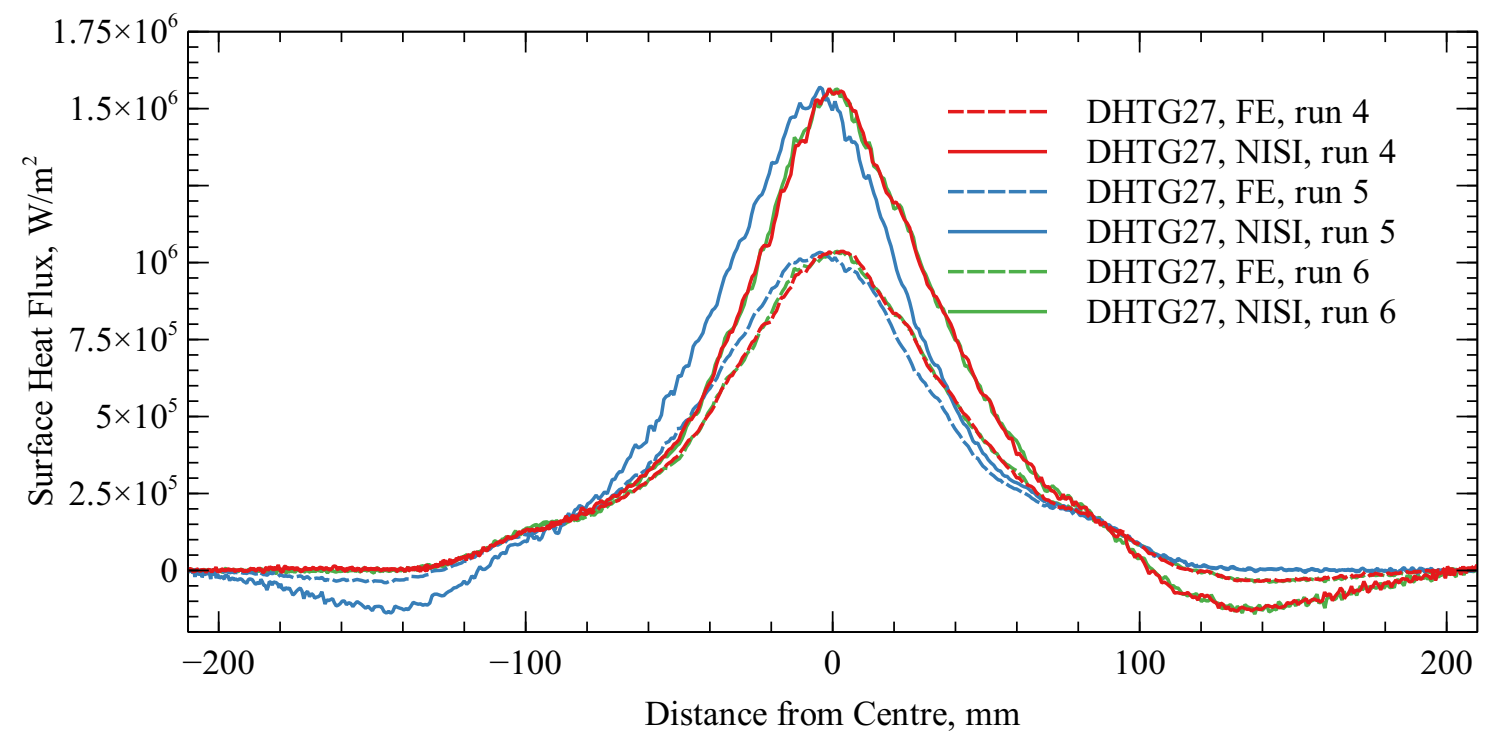

(b) Surface Heat Flux

Fig. 13 Measurements of temperature and heat flux for Condition 1b in PWK4. 
Distance from Centre, $\mathrm{mm}$

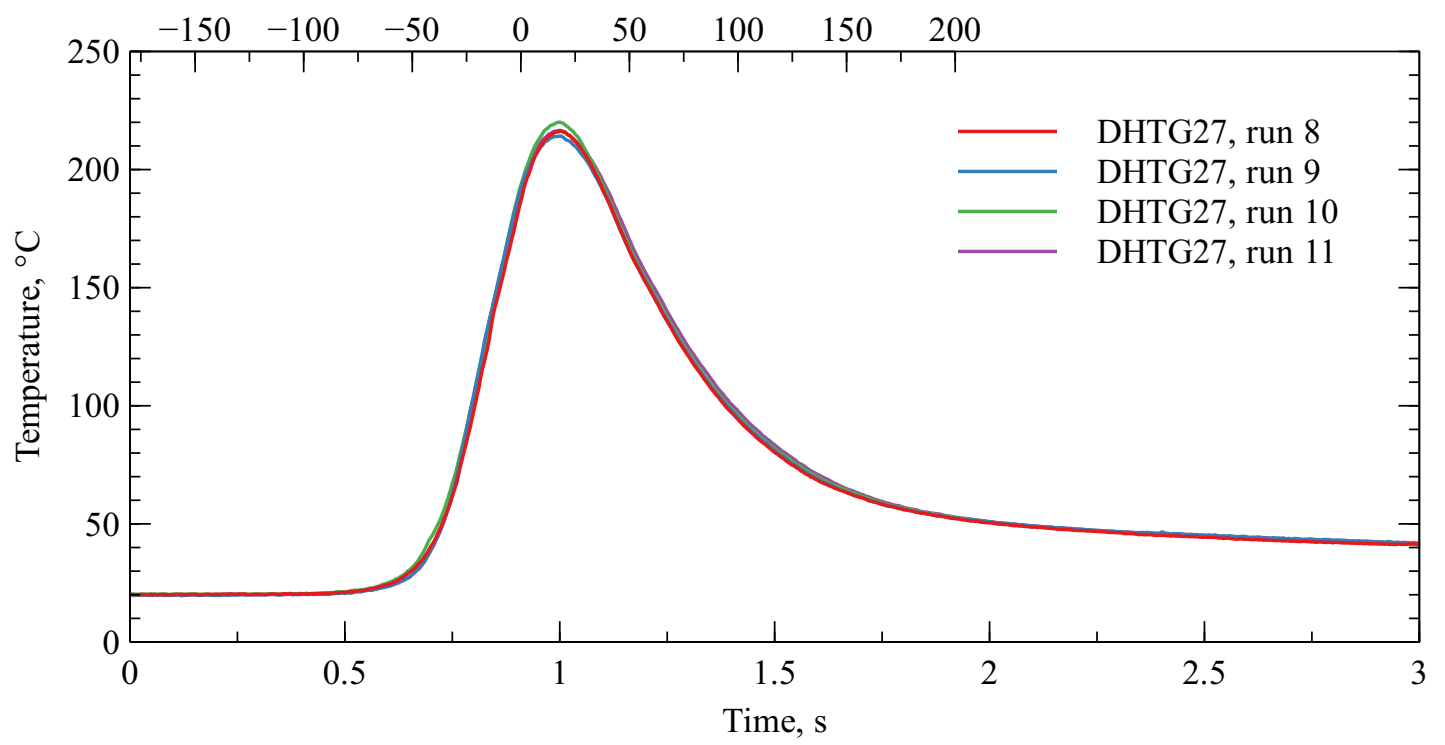

(a) Temperature

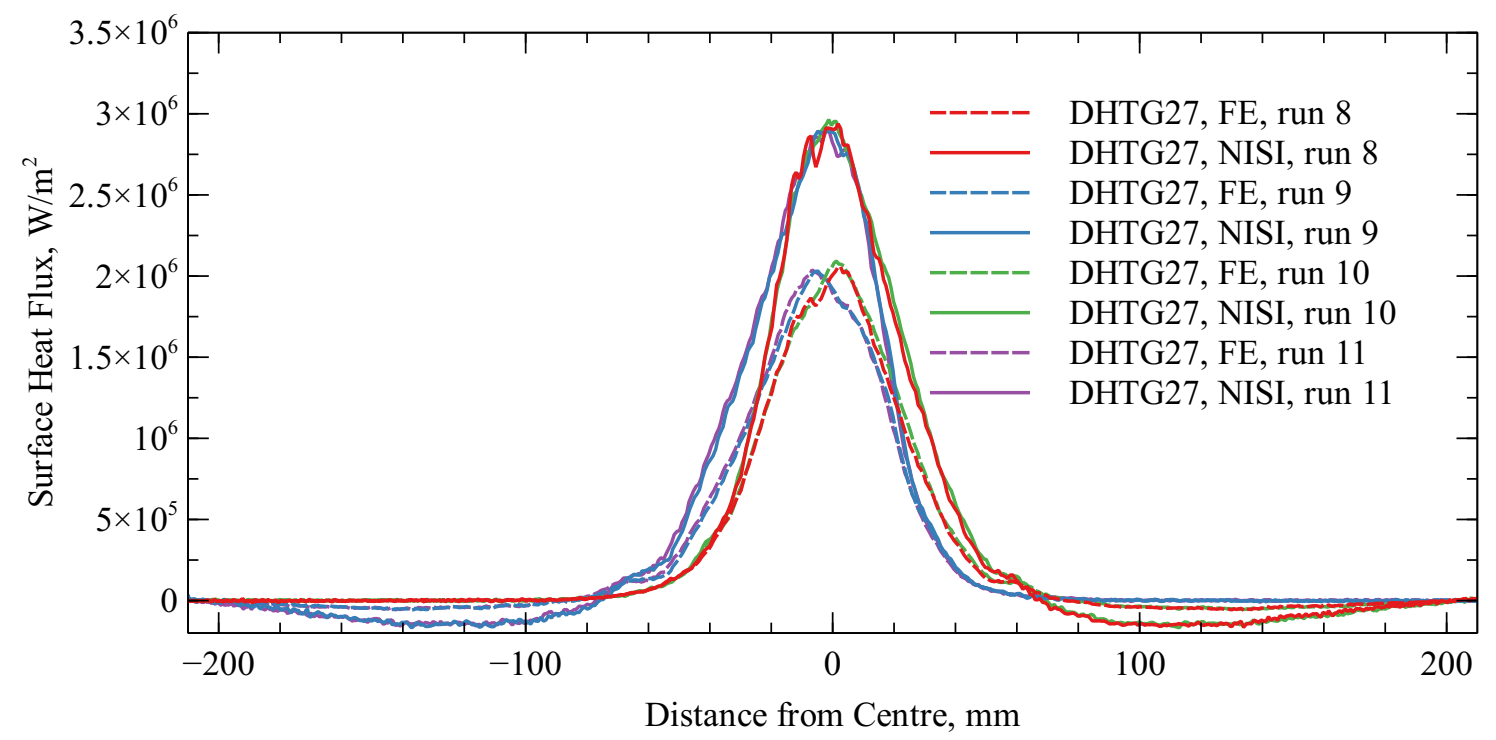

(b) Surface Heat Flux

Fig. 14 Measurements of temperature and heat flux for Condition 2 in PWK4. 


\section{Conclusion}

A probe consisting of a Diamond Heat Transfer Gauge in a copper hemisphere has been used to measure stagnation point heat fluxes in a plasma wind tunnel. The impulse response of the probe was found across a range of initial temperatures from a Finite Element model, and from an experimental approach with a laser-based calibration and subsequent system identification using the NISI method. The impulse responses from the two methods show good agreement at low temperatures, but increasingly poor agreement at elevated temperatures. The reason for the difference in impulse response is unknown, and further work must be done to identify the cause, beginning with an experiment to measure the reflectivity of the probe surface at a range of temperatures.

The probe was used at three flow conditions in the PWK4 facility. The heat flux was calculated from recorded temperature signals using a version of the Sequential Function Specification Method, modified to account for non-linear behaviour, using both the NISI and FE impulse responses. Differences in the impulse responses led to differences in the measured heat fluxes of up to $55 \%$ between the NISI and FE derived heat fluxes and up to $15 \%$ between the two gauges at the same flow condition. A measurement of heat flux taken with a calorimetric probe at Condition 1a agrees more closely with the heat flux calculated using FE-derived impulse responses for DHTG27, and using NISI-derived impulse responses for DHTG26, although an unaccounted for difference in surface catalycity could affect this observation. Significant surface fluctuations could not be identified in the heat transfer data, future work to improve the signal to noise ratio in such an electrically noisy environment will be required to make these measurements.

\section{Acknowledgements}

Thanks to Gregory King for his precise work assembling the Diamond Heat Transfer Gauges and to all the operators of the PWK4 facility.

\section{References}

[1] Auweter-Kurtz, M., Kurtz, H. L., and Laure, S., "Plasma generators for re-entry simulation," Journal of Propulsion and Power, Vol. 12, No. 6, 1996, pp. 1053-1061.

[2] Loehle, S., Fasoulas, S., Herdrich, G. H., Hermann, T. A., Massuti-Ballester, B., Meindl, A., Pagan, A. S., and Zander, F., "The plasma wind tunnels at the institute of space systems: current status and challenges," 32nd AIAA Aerodynamic Measurement Technology and Ground Testing Conference, 2016, p. 3201.

[3] Löhle, S., Auweter-Kurtz, M., and Eberhart, M., "Local enthalpy measurements in a supersonic arcjet facility," Journal of Thermophysics and Heat Transfer, Vol. 21, No. 4, 2007, pp. 790-795.

[4] Powars, C. A., Kennedy, W. S., and Rindal, R. A., "Heat flux measurement using swept null point calorimetry," Journal of Spacecraft and Rockets, Vol. 9, No. 9, 1972, pp. 668-672.

[5] Loehle, S., Battaglia, J.-L., Jullien, P., Ootegem, B. V., Lasserre, J.-P., and Couzi, J., "Improvement of High Heat Flux Measurement Using a Null-Point Calorimeter," Journal of Spacecraft and Rockets, Vol. 45, No. 1, 2008, pp. 76-81.

[6] Nawaz, A., Driver, D. M., Terrazas-Salinas, I., and Sepka, S., "Surface catalysis and oxidation on stagnation point heat flux measurements in high enthalpy arc jets," 44th AIAA Thermophysics Conference, 2013, p. 3138.

[7] Loehle, S., Nawaz, A., Herdrich, G. H., Fasoulas, S., Martinez, E., and Raiche, G., "Comparison of Heat Flux Gages for High Enthalpy Flows-NASA Ames and IRS," 46th AIAA Thermophysics Conference, 2016, p. 4422.

[8] Zander, F., Hermann, T. A., and Loehle, S., "Plasma wind tunnel flow analysis with high speed imaging," 32nd AIAA Aerodynamic Measurement Technology and Ground Testing Conference, 2016, p. 3202.

[9] Hermann, T., Löhle, S., Fasoulas, S., and Andrianatos, A., "Tomographic optical emission spectroscopy of a high enthalpy air plasma flow," Applied optics, Vol. 55, No. 36, 2016, pp. 10290-10298.

[10] Schultz, D. L., and Jones, T., "Heat-Transfer Measurements in Short-Duration Hypersonic Facilities.” Tech. rep., DTIC Document, 1973.

[11] Ozisik, M. N., Inverse heat transfer: fundamentals and applications, CRC Press, 2000.

[12] Ljung, L., System identification: theory for the user, Prentice-hall, 1987. 
[13] Penty Geraets, R. T., McGilvray, M., Doherty, L., Morgan, R. G., James, C. M., Vanyai, T., and Buttsworth, D. R., "Development of a fast-response calorimeter gauge for hypersonic ground testing," 33rd AIAA Aerodynamic Measurement Technology and Ground Testing Conference, 2017, p. 3238.

[14] Penty Geraets, R. T., McGilvray, M., Williams, B., and Shah, P., "Laser-based Calibration and Processing Technique for a Robust Fast-Response Surface Heat Transfer Gauge," 2018 Joint Thermophysics and Heat Transfer Conference, 2018 , p. 3772.

[15] Battaglia, J.-L., Cois, O., Puigsegur, L., and Oustaloup, A., "Solving an inverse heat conduction problem using a non-integer identified model," International Journal of Heat and Mass Transfer, Vol. 44, No. 14, 2001, pp. 2671-2680.

[16] Lohle, S., "Characterisation of a heat flux sensor using short pulse laser calibration," Review of Scientific Instruments, Vol. 78, 2007.

[17] Lohle, S., Fuchs, U., Digel, P., Hermann, T., and Battaglia, J.-L., "Analysing inverse heat conduction problems by the analysis of the system impulse response function," Inverse Problems in Science and Engineering, 2013.

[18] Beck, J. V., Blackwell, B., and Clair Jr, C. R. S., Inverse heat conduction: Ill-posed problems, James Beck, 1985.

[19] Collins, M., Chana, K., and Povey, T., "New technique for the fabrication of miniature thin film heat flux gauges," Measurement Science and Technology, Vol. 26, No. 2, 2015, p. 025303.

[20] Review, P. M., “Thermophysical Data on Platinum,” Platinum Metals Review, 1984, p. 164.

[21] Wort, C., Sweeney, C., Cooper, M., Scarsbrook, G., and Sussmann, R., "Thermal properties of bulk polycrystalline CVD diamond," Diamond and Related Materials, Vol. 3, No. 9, 1994, pp. 1158-1167.

[22] Cerisier, M., “Caracterisation Optique du Cuivre ARA,” Tech. rep., CEA, Le Barp, France, 2006.

[23] Vargaftik, N. B., "Handbook of physical properties of liquids and gases-pure substances and mixtures," 1975.

[24] Zhang, J., Wang, Y., Cheng, P., and Yao, Y. L., "Effect of pulsing parameters on laser ablative cleaning of copper oxides," Journal of applied physics, Vol. 99, No. 6, 2006, p. 064902.

[25] Coleman, H. W., and Steele, W. G., Experimentation, validation, and uncertainty analysis for engineers, John Wiley \& Sons, 2009. 